\title{
Dexpanthenol reduces fibrosis and aids repair following nerve laceration and neurorrhaphy
}

\author{
GOKHAN KARAHAN ${ }^{1}$, HUSEYIN KAYA ${ }^{2}$, RECEP SELÇUK EYCEYURT ${ }^{1}$, \\ MUMIN ALPER ERDOGAN ${ }^{3}$, GURKAN YIGITTURK ${ }^{4}$ and OYTUN ERBAS ${ }^{5}$
}

\author{
${ }^{1}$ Orthopedics and Traumatology Department, Bozyaka Training and Research Hospital, Izmir 35110; \\ ${ }^{2}$ Orthopedics and Traumatology Department, Faculty of Medicine, Ege University, Izmir 35040; \\ ${ }^{3}$ Faculty of Medicine, Department of Physiology, Izmir Katip Celebi University, Karabaglar, Izmir 35000; \\ ${ }^{4}$ Department of Histology and Embryology, Faculty of Medicine, Muğla University, Menteşe, Muğla 48000; \\ ${ }^{5}$ Department of Physiology, Faculty of Medicine, Istanbul Bilim University, Şişli, Istanbul 34000, Turkey
}

Received April 9, 2020; Accepted December 1, 2020

DOI: $10.3892 /$ etm.2021.9639

\begin{abstract}
The aim of the present study was to investigate the effect of dexpanthenol on nerve healing following neurorrhaphy in lacerated peripheral nerves. A total of 30 mature Sprague Dawley rats were used. Surgical sciatic nerve dissection and repair was performed on an experimental group of 20 rats. The remaining 10 rats were designated as the control group. The experimental group was divided into 2 subgroups. The surgery + saline group (SSLE; $\mathrm{n}=10$ ) was given $1 \mathrm{ml} / \mathrm{kg} 0.9 \%$ sodium chloride saline intraperitoneally. The surgery + dexpanthenol group (SDPL; $n=10)$ rats were given $500 \mathrm{mg} / \mathrm{kg} /$ day dexpanthenol intraperitoneally. Histological evaluation of the sciatic nerve tissue revealed that the fibrosis score was significantly lower in the SDPL group than in the SSLE group $(\mathrm{P}<0.001)$. Electrophysiological evaluation of compound muscle action potential (CMAP) indicated that the CMAP level in the SDPL group was significantly higher than that of the SSLE group $(\mathrm{P}<0.001)$, and the CMAP latency period was lower in the SDPL group compared with the SSLE group $(\mathrm{P}<0.001)$. In addition, the SDPL group malondialdehyde level was significantly lower than that of the SSLE group $(\mathrm{P}<0.001)$. Functional evaluation with an inclined plane test revealed a significant difference between the SSLE $\left(39.6 \pm 5.5^{\circ}\right)$ and SDPL $\left(79.1 \pm 6.93^{\circ}\right)$ groups $(\mathrm{P}<0.001)$. Dexpanthenol was observed to have a positive effect on nerve tissue repaired with neurorrhaphy in a rat sciatic model of laceration-type injuries similar to those frequently encountered in the clinic.
\end{abstract}

Correspondence to: Dr Gokhan Karahan, Orthopedics and Traumatology Department, Bozyaka Training and Research Hospital, 59 Saim Çıkrıkçı Caddesi, Karabaglar, Izmir 35110, Turkey

E-mail: hgk139@hotmail.com

Key words: nerve healing, dexpanthenol, primary neurorrhaphy, fibrosis score, rat sciatic model

\section{Introduction}

Peripheral nerve injury commonly occurs in the form of laceration due to trauma. Where possible, primary end-to-end repair is the best repair option for lacerated nerves and includes the techniques of epineural and fascicular repair (1-3). It has been increasingly recognized that nerve repair is not simply a mechanical problem and that surgery is not the only key to recovery (4). Several factors may influence nerve regeneration. While contact with Schwann cell basal laminae and Schwann cell development are important at the cellular level, inflammatory and neurotrophic factors are important at the extracellular level (5-7). Numerous treatments that may improve nerve recovery at the cellular and extracellular level are still at an experimental stage and have yet to progress to the clinic. In addition to immunosuppressive agents such as tacrolimus (8), healing accelerating agents, including stem cells and cytokines (9-11), and antioxidative agents, including trimetazidine (12), have been used in experimentally and their effectiveness has been demonstrated. The quality of nerve regeneration and reinnervation time are crucial for an ideal functional outcome following nerve injury, but traditional nerve repair alone cannot effectively shorten reinnervation time to ensure a satisfactory recovery $(13,14)$.

The inflammatory process that occurs following peripheral nerve injury increases fibrosis and oxidative stress levels. Excess scar tissue can subsequently develop and exert a negative influence on signal transmission within neural tubes. It is thought that agents with anti-inflammatory properties may decrease the oxidative stress load and contribute to healing of nerve injuries. Dexpanthenol is an alcohol analogue of pantothenic acid (PA). Also known as provitamin B5, PA specifically exerts anti-inflammatory and antioxidant effects. Dexpanthenol is known to increase the reduced levels of glutathione, coenzyme A (CoA; especially mitochondrial $\mathrm{CoA}$ ) and adenosine-5'-triphosphate synthesis within a cell. This provides support to anti-inflammatory and antioxidant activities that themselves serve major roles in cellular defense and repair systems against oxidative stress and the inflammatory response (15). 
The aim of the present study was to use an experimental sciatic nerve injury model to investigate the potential effect of dexpanthenol on nerve conduction and the healing of peripheral nerve injuries following laceration and treatment with epineurial neurorrhaphy.

\section{Materials and methods}

Animals. In the present study, 30 mature (5-6 months), male Sprague-Dawley albino rats each weighing 200-240 g were used. The animals were fed and given water ad libitum and housed in pairs in metal cages in a temperature and humidity-controlled environment $\left(22 \pm 2^{\circ} \mathrm{C}, 40-70 \%\right.$ relative humidity) under a $12 \mathrm{~h}$ light/dark cycle. The Committee for Animal Research of Demiroglu Science University (approval no. 20172805-3) approved the experimental procedures used in the present study and the research strictly conformed to the American Psychological Association Committee on Animal Research and Ethics Guidelines for Ethical Conduct in the Care and Use of Nonhuman Animals in Research (13).

Experimental protocol. A total of 20 rats were designated as the experimental group, and surgical sciatic nerve dissection and repair surgery was performed on each. The remaining 10 rats served as the normal control group $(n=10)$; no surgical operation was performed on these animals and no medications were administered. The experimental group of 20 was divided into 2 subgroups. The surgery + saline rats (SSLE; $\mathrm{n}=10$ ) were a placebo group and were given $1 \mathrm{ml} / \mathrm{kg} 0.9 \%$ sodium chloride saline intraperitoneally. The surgery + dexpanthenol group (SDPL; $\mathrm{n}=10$ ) rats were given $500 \mathrm{mg} / \mathrm{kg} /$ day dexpanthenol (Bepanthen; $500 \mathrm{mg}$ ampoule; Bayer AG) intraperitoneally. All of the injections were administered for 12 weeks. At the conclusion of the treatment period, a motor function test and electromyography (EMG) recordings were performed. Blood samples were collected via tail vein puncture $(1 \mathrm{ml})$ using an insulin syringe and placed into tubes containing heparin for biochemical analysis. The animals were sedated with a ketamine/xylazine mixture $(75 \mathrm{mg} / \mathrm{kg}$ ketamine and $10 \mathrm{~g} / \mathrm{kg}$ xylazine) and euthanized via decapitation, after which sciatic nerve samples were collected for immunohistochemistry analysis.

Surgical procedure. Following the induction of general anesthesia $(75 \mathrm{mg} / \mathrm{kg}$ ketamine and $10 \mathrm{~g} / \mathrm{kg}$ xylazine, via intraperitoneal injection), the rats were fixed to the operating surface in the prone position. Both sciatic nerves were exposed from $1 \mathrm{~cm}$ distal of the sciatic notch to $1 \mathrm{~cm}$ distal to the trifurcation of the nerve using an aseptic technique. Nerve segments above the trifurcation, each $3-3.5 \mathrm{~cm}$ in length, were carefully dissected to isolate the sciatic nerve from the surrounding soft tissue. The nerves were then transected using micro scissors at $1.5 \mathrm{~cm}$ above the trifurcation (starting point of the tibial nerve, common peroneal nerve and caudal sural cutaneous nerve). The nerves were repaired with 3 epineurial sutures (Ethilon 9-0; Ethicon Inc.) by the same surgeon (Fig. 1). The wound was closed with 3-0 Vicryl (Ethicon, Inc.) and the rats were allowed to heal. Upon recovery from anesthesia, the rats were returned to their cages and allowed to freely consume food and water. Lipid peroxidation was determined in the tissue samples by measuring malondialdehyde (MDA) levels as a thiobarbituric acid reactive substance (TBARS), as previously described (16). Briefly, trichloroacetic acid and TBARS (Sigma-Alrich; Merck KGaA) reagents were added to the tissue samples, then mixed and incubated at $100^{\circ} \mathrm{C}$ for $60 \mathrm{~min}$. After cooling on ice, the samples were centrifuged at $1,000 \mathrm{x} \mathrm{g}$ for $20 \mathrm{~min}$ at $4^{\circ} \mathrm{C}$ and the absorbance of the supernatant was read at $535 \mathrm{~nm}$ using a microplate reader immediately. MDA levels were calculated from the standard calibration curve using tetraethoxypropane and expressed as $\mathrm{nmol} / \mu \mathrm{g}$ protein.

Electrophysiological recordings. The rats were anesthetized with a combination of ketamine hydrochloride at a dose of $80 \mathrm{mg} / \mathrm{kg}$ (Alfamine; Alfasan International B.V.) and xylazine hydrochloride at a dose of $10 \mathrm{mg} / \mathrm{kg}$ (Alfazyne, Alfasan International B.V.). Electrophysiological recordings (EMG studies) were performed in all of the groups. EMG results were obtained 3 times from the sciatic nerve stimulated supramaximally (intensity, $10 \mathrm{~V}$; duration, $0.05 \mathrm{msec}$; frequency, $1 \mathrm{~Hz}$; range, 0.5-5000 Hz; sampling rates, $40 \mathrm{kHz} / \mathrm{s}$ ) using a bipolar subcutaneous needle stimulation electrode (BIOPAC Systems, Inc.; model no. EL451; 25 mm x 30 g concentric bipolar electrode) placed at the sciatic notch. The compound muscle action potential (CMAP) was recorded from 2-3 interosseous muscles using unipolar platinum electrodes. The data were evaluated using Biopac Student Lab Pro version 3.6.7 software (BIOPAC Systems, Inc.) with distal latency and amplitude of the CMAP as parameters. During the EMG recordings, the rectal temperature of the rats was monitored with a rectal probe (model no. HP Viridia 24C; Hewlett-Packard Company) and the temperature of each rat was maintained at $\sim 36-37^{\circ} \mathrm{C}$ with a heating pad. All of the tests were performed between 10:00 a.m. and 2:00 p.m.

Assessment of motor function. The motor performance of the rats was evaluated using an inclined plane test as described by Rivlin and Tator (17). Briefly, rats were placed in an oblique position to the long axis of an inclined plane. The initial angle of the inclined plane was $10^{\circ}$. The incline angle was slowly increased and the maximum angle of the plane at which the rat maintained its position for $5 \mathrm{sec}$ without falling was recorded as the motor score. The angle was measured 3 times in each rat to determine an average value.

Histology and quantitative immunohistochemistry. Intracardiac $4 \%$ formaldehyde perfusion (at room temperature for $4 \mathrm{~min}$ ) was performed for histology and quantitative immunohistochemistry analysis. Briefly, the sciatic nerves were embedded in paraffin, sectioned at $5 \mu \mathrm{m}$ thickness with a microtome (model no. Leica RM 2145; Leica Microsystems $\mathrm{GmbH}$ ) and stained with hematoxylin and eosin. The thickness of the sciatic epineurium nerve was measured, and the stained tissue sections were then examined with an Olympus C-5050 digital camera mounted on an Olympus BX51 microscope (Olympus Corporation). The Image-Pro Express 4.5 program (Media Cybernetics, Inc.) was used to measure the total number of axons, the thickness of the perineural layers in the middle regions of the grafts, and the level of fibrosis 
A

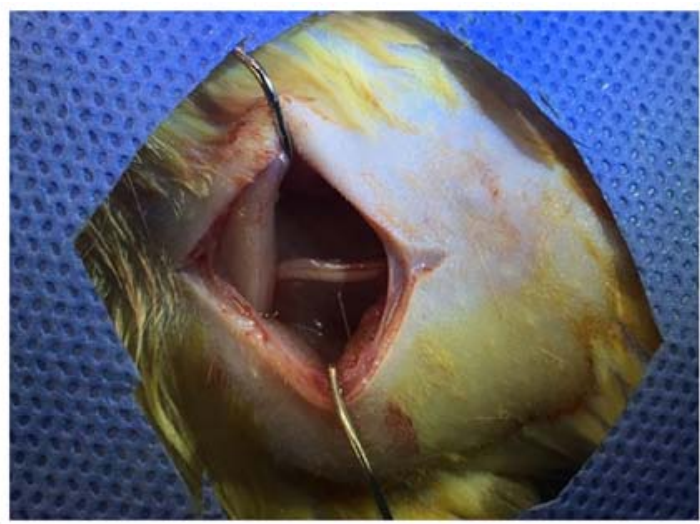

c

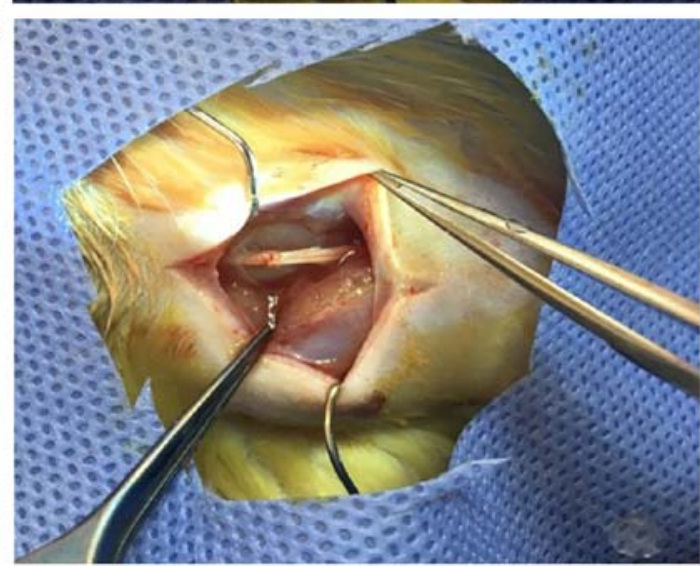

B

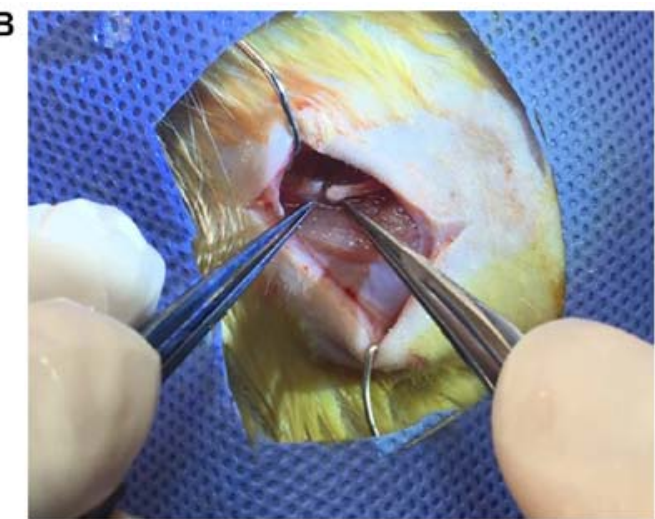

D

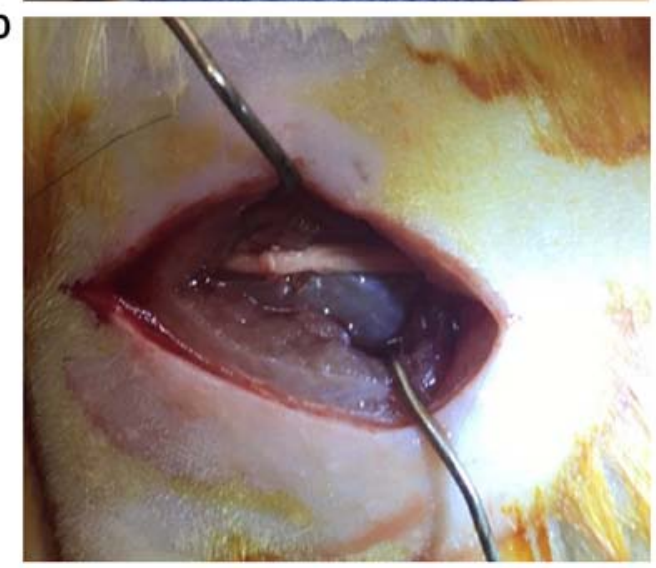

Figure 1. Surgical procedure for the experimental groups. (A) The sciatic nerve was exposed $1 \mathrm{~cm}$ distal of the sciatic notch to $1 \mathrm{~cm}$ distal to the trifurcation. (B) Nerves were transected using micro scissors. (C) Nerves were repaired with epineurial sutures. (D) View of nerve healing after neurorraphy.

covering these layers in the histological specimens of each group. These data were used for statistical analyses.

For the immunohistochemical examination, sections were incubated with hydrogen peroxide (10\%) for $30 \mathrm{~min}$ at room temperature to eliminate endogenous peroxidase activity and then blocked with $10 \%$ normal goat serum (Invitrogen; Thermo Fisher Scientific, Inc.) for $1 \mathrm{~h}$ at room temperature. Subsequently, sections were incubated with a primary antibody for nerve growth factor (NGF; 1:100; Santa Cruz Biotechnology Inc.; cat. no. sc-365944) for $24 \mathrm{~h}$ at $4^{\circ} \mathrm{C}$. Antibody detection was conducted using the Histostain-Plus Bulk kit (Invitrogen; Thermo Fisher Scientific, Inc.; cat. no. 85-8943) according to the manufacturer's protocol for rabbit immunoglobulin $\mathrm{G}$, and 3,3' diaminobenzidine was used to visualize the final product. All sections were washed with PBS and examined under an Olympus BX51 microscope and photographed with the Olympus C-5050 digital camera. A total of 6 sections from each study animal and 10 different fields from each of these sections were used for quantitative immunohistochemistry analysis. Two blinded observers counted the total number of immune-positive Schwann cells and the number of axons under a light microscope at x10 and x20 magnification. The data are presented as the mean \pm SD.

Statistical analysis. SPSS version 20.0 (IBM Corp.) was used to perform statistical analysis. All experiments were performed in triplicate and the data for each group are presented as the mean \pm SD. Statistical analysis was performed using one-way ANOVA with a Tukey post hoc test to determine statistical significance. $\mathrm{P}<0.05$ was considered to indicate a statistically significant difference.

\section{Results}

Functional evaluation. Analysis of the inclined plane test revealed that the results in the SDPL group $\left(79.1 \pm 6.93^{\circ}\right)$ were more similar to that of the control group $\left(88.7 \pm 5.8^{\circ}\right)$ than those in the SSLE group $\left(39.6 \pm 5.5^{\circ}\right)$ but there is no statistically significance between these groups. Statistical evaluation demonstrated a significant difference between the control and SSLE groups $(\mathrm{P}<0.001)$ and the SSLE and SDPL groups $(\mathrm{P}<0.001$; Table I).

Results of histopathological evaluation. Histological evaluation of sciatic nerve tissue revealed that the fibrosis score was significantly lower in the SDPL group when compared with the SSLE group $(\mathrm{P}<0.001)$. Increased NGF expression and increased Schwann cell numbers were seen in the SDPL group in comparison with the SSLE group $(\mathrm{P}<0.001)$. The histopathological evaluation of the number of axons in the sciatic nerve demonstrated that the results in the SDPL group were significantly higher than those in the SSLE group $(\mathrm{P}<0.001)$ (Table II; Fig. 2).

Results of electrophysiological studies. EMG results indicated that the CMAP level was significantly lower in the SSLE group when compared with the control group $(\mathrm{P}<0.001)$. The CMAP level of the SDPL group was significantly higher than 
Table I. Comparison of EMG CMAP latency, EMG CMAP amplitude and inclined plane score between groups.

\begin{tabular}{lccc}
\hline Parameter & Normal control & Surgery + saline group & Surgery + dexpanthenol group \\
\hline EMG CMAP latency $(\mathrm{ms})$ & $2,31 \pm 0,19$ & $3,74 \pm 0,15^{\mathrm{a}}$ & $2,9 \pm 0,19^{\mathrm{c}}$ \\
EMG CMAP amplitude $(\mathrm{mV})$ & $12,65 \pm 1,1$ & $2,36 \pm 0,42^{\mathrm{b}}$ & $7,02 \pm 0,97^{\mathrm{d}}$ \\
Inclined plane score $\left(^{\circ}\right)$ & $88,7 \pm 5,8$ & $39,6 \pm 5,5^{\mathrm{b}}$ & $79,1 \pm 6,93^{\mathrm{d}}$ \\
\hline
\end{tabular}

${ }^{\mathrm{a}} \mathrm{P}<0.05$ and ${ }^{\mathrm{b}} \mathrm{P}<0.001$ vs. normal control group; ${ }^{\mathrm{c}} \mathrm{P}<0.001$ and ${ }^{\mathrm{d}} \mathrm{P}<0.0001$ vs. surgery + saline group. EMG, electromyography; CMAP, compound muscle action potential.

Table II. Comparison of NGF expression in Schwann cells, total axon number and fibrosis score between groups.

\begin{tabular}{|c|c|c|c|}
\hline Parameter & Normal control & Surgery+saline group & Surgery + dexpanthenol group \\
\hline NGF expression on Schwann cells (\%) & $41,8 \pm 9,6$ & $4,6 \pm 1,1^{\mathrm{a}}$ & $12,5 \pm 4,2^{\mathrm{c}}$ \\
\hline Total axon number & $1450,2 \pm 85,6$ & $315,8 \pm 45,9^{b}$ & $514,2 \pm 30,06^{\mathrm{c}}$ \\
\hline Fibrosis score (\%) & $0,9 \pm 0,08$ & $68,5 \pm 6,2^{\mathrm{b}}$ & $25,4 \pm 5,65^{\mathrm{d}}$ \\
\hline
\end{tabular}

${ }^{a} \mathrm{P}<0.05$ and ${ }^{\mathrm{b}} \mathrm{P}<0.001$ vs. normal control group; ${ }^{\mathrm{C}} \mathrm{P}<0.001$ and ${ }^{\mathrm{d}} \mathrm{P}<0.0001$ vs. surgery + saline group. NGF, nerve growth factor.

A

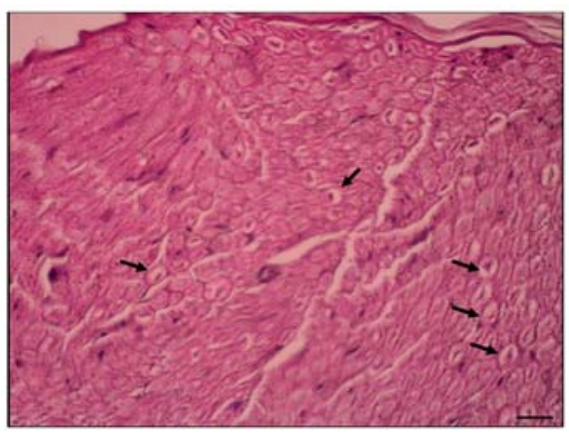

C

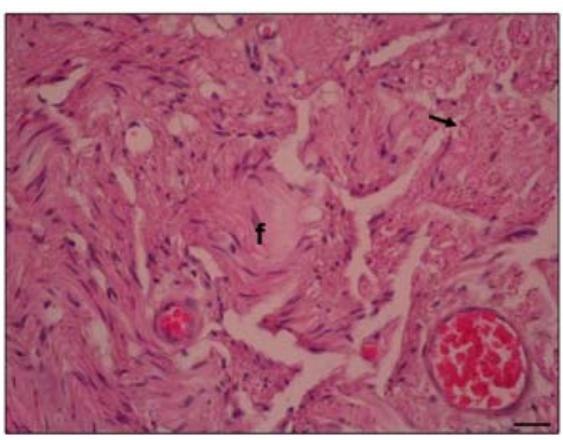

E

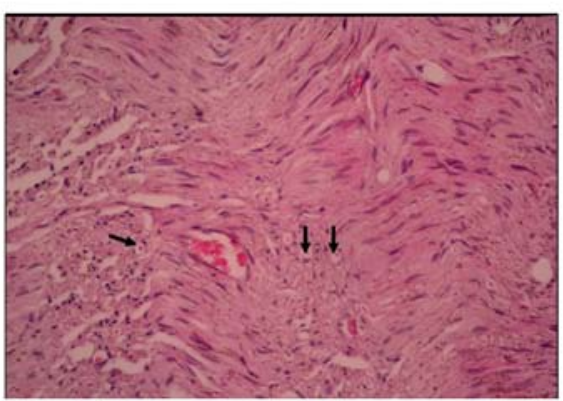

B
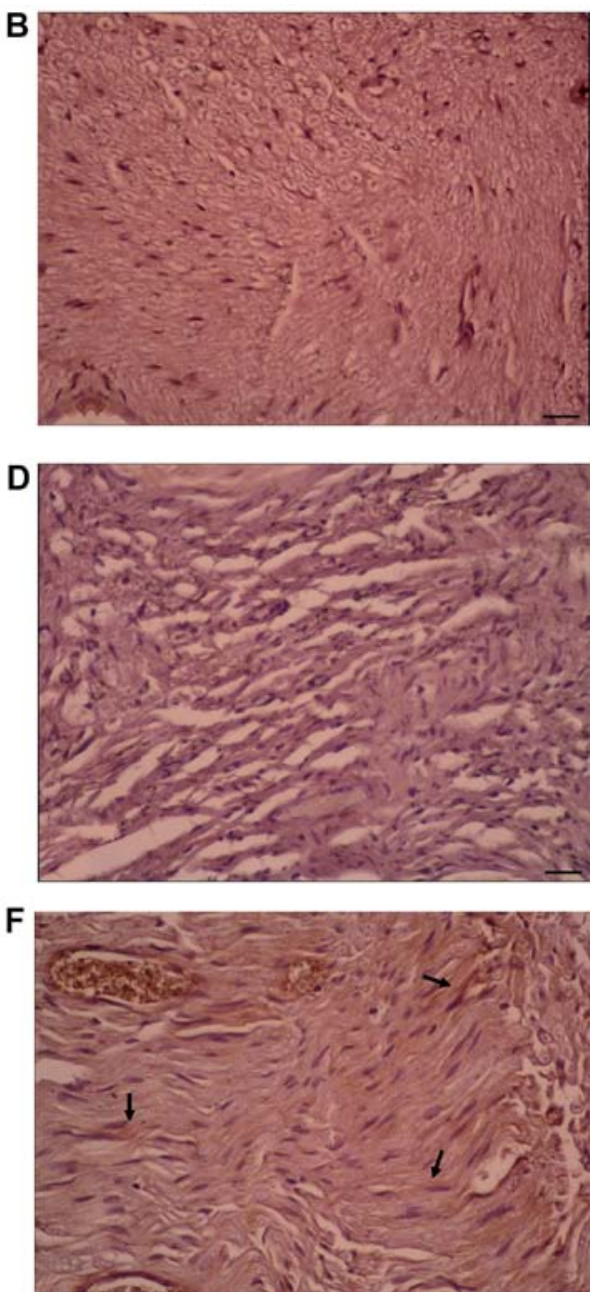

Figure 2. H\&E and NGF immunostaining. (A) H\&E and (B) NGF in the control group. A typical axon and Schwann cell count was seen. (C) H\&E and (D) NGF in the surgery + saline group. Fibrosis was present and the number of axons and Schwann cells, along with the intensity of NGF expression, were reduced compared to the control. (E) H\&E and (F) NGF in the surgery + dexpanthenol group. Increased numbers of axons and Schwann cells, along with an increased NGF expression were observed compared with the controls (magnification, x20, scale bars indicate $200 \mu \mathrm{m}$ ). Arrows indicate axons and Schwann cells and (f) indicates fibrosis. H\&E, hematoxylin and eosin; NGF, nerve growth factor. 

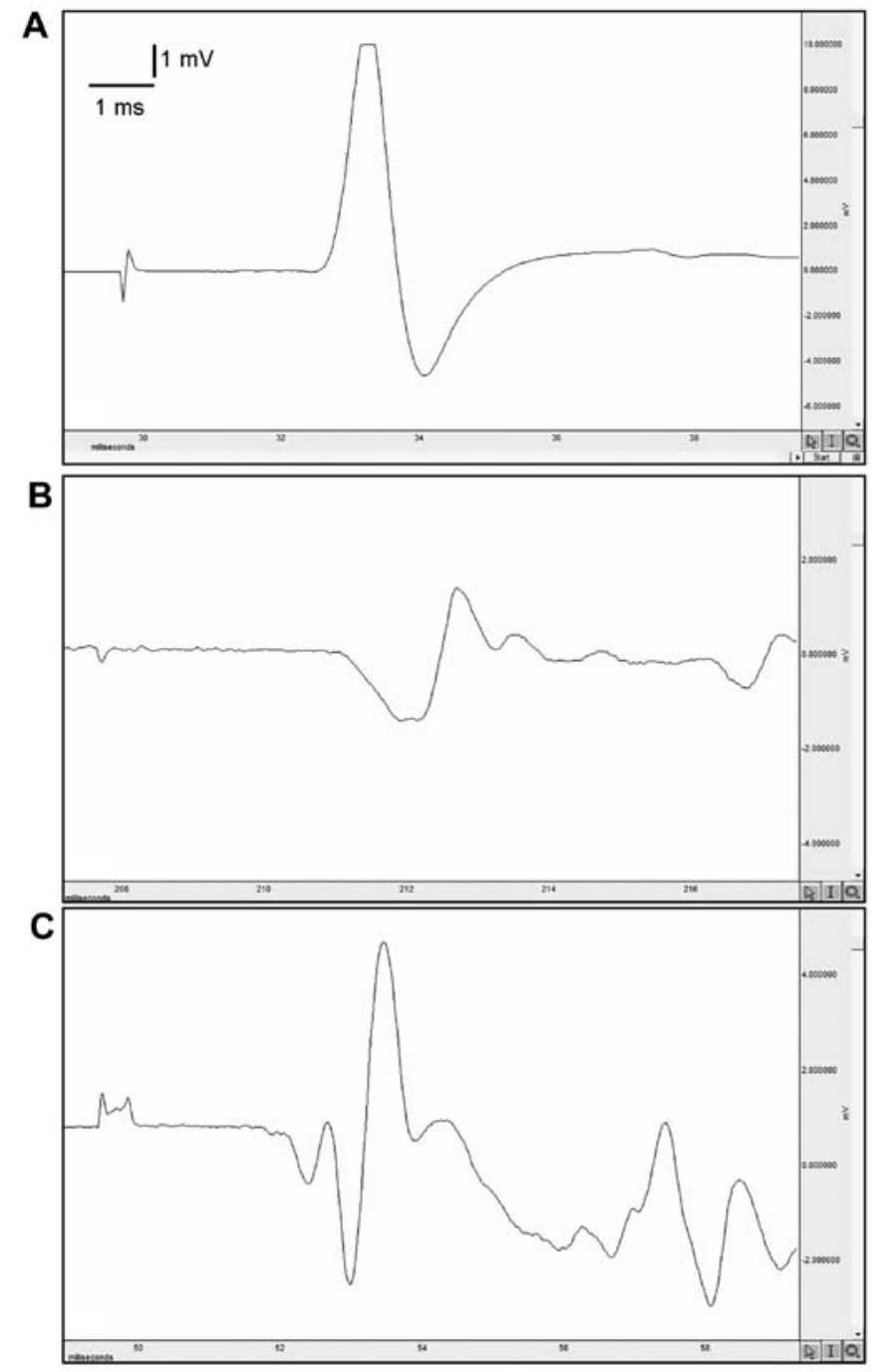

Figure 3. Electromyography recordings. Electromyography readings in (A) the control group, (B) the surgery + saline group and (C) the surgery + dexpanthenol group.

that of the SSLE group $(\mathrm{P}<0.001)$. The CMAP latency period was lower in the SDPL group in comparison with the SSLE group ( $\mathrm{P}<0.001$; Table II; Fig. 3).

Evaluation of oxidative stress. The level of MDA, which was used as a marker of oxidative stress, was higher in the SSLE group when compared with the control group $(\mathrm{P}<0.0001)$. When the SDPL group was compared with the SSLE group, MDA levels were significantly lower ( $\mathrm{P}<0.001$; Fig. 4).

\section{Discussion}

Peripheral nerve injuries are a common clinical problem and often result in long-term functional impairment. Despite advances in microsurgical techniques, the functional outcome of peripheral nerve trauma is rarely completely satisfactory and has resulted in extensive experimental research to develop methods to improve regeneration (13). The rat sciatic nerve model has been widely used in these studies, and various regeneration assessment methods have been described (18).

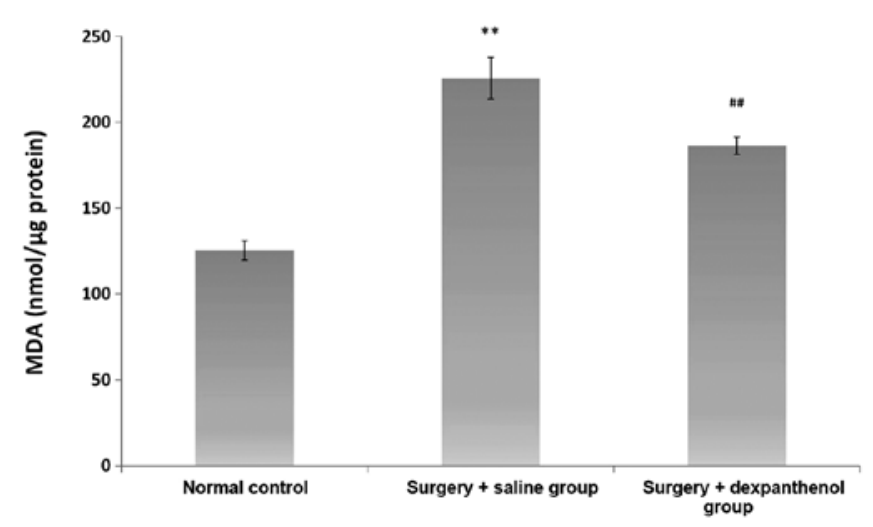

Figure 4. MDA levels in each group. The surgery + saline group MDA levels were higher than those in the control group. The surgery + dexpanthenol group MDA levels were significantly lower than those in the surgery + saline group. ${ }^{* *} \mathrm{P}<0.0001$ vs. normal control and ${ }^{\# \#} \mathrm{P}<0.001$ vs. surgery + saline. MDA, malondialdehyde.

The results of the present study revealed that dexpanthenol had a statistically significant effect on nerve recovery compared with the control group post epineurial neurosurgery in the repair of a laceration-type peripheral nerve injury. Previous research has demonstrated that fibrosis occurring during nerve healing adversely affected functional results (19). A number of studies have revealed that dexpanthenol decreases fibrosis $(20,21)$. Ermis et al (21) investigated intraurethral fibrosis with histopathological evaluation that used fibrosis and inflammation scar scoring and demonstrated that dexpanthenol decreased fibrosis of the epithelial tissue. In the present study, the fibrosis tissue at the field of the nerve anastomosis was scored and evaluated. The influence of the decrease in fibrous tissue on axonal advancement was assessed histopathologically. The results indicated that the fibrosis score was greater in the SSLE group than in the control and significantly lower in the SDPL than the SSLE group. This influence was observed histopathologically as an increase in the number of axons and Schwann cells in the distal region of the anastomosis.

The most commonly referenced evaluation method in peripheral nerve injury models is the electrophysiological method $(13,22)$. Ogden et al $(15)$ examined the effect of dexpanthenol on compression type injuries of the sciatic nerve and found no significant influence when used alone in treatment; however, electrophysiological tests were not performed. Laceration-type peripheral nerve injuries are frequently encountered in the clinic, and in the present study, the assessment of the influence of dexpanthenol on this type of injury included electrophysiological methods, which demonstrated significant healing when compared with the control group.

One of the main factors contributing to neural damage following injury is oxidative stress (23). Studies have shown that decreasing oxidative stress after a peripheral nerve injury may stimulate the repair process and improve functional recovery $(24,25)$. MDA is a product of lipid oxidation and it is a commonly used index for oxidative stress (26). Tutun et al (27) investigated the effect of dexpanthenol on tissue damage and lipid oxidation in a rat testis torsion model and found a significant decrease in the serum MDA level (28). In the present study, oxidative stress was evaluated using the level of serum MDA 
and it was observed that the MDA level was significantly lower in the SDPL group when compared with the SSLE group.

Functional results commonly used in experimental animal nerve studies include histopathological evaluation, electrophysiological studies and measurements of biomarkers, such as lipid peroxidation $(13,22,24)$. Many procedures and evaluation scales have been developed for the proper measurement of functional outcome. Some of the most common assessments used are the Basso, Beattie and Bresnahan (BBB) scale (29), the Tarlov open field test (30) and the inclined plane test. In the present study, the inclined plane test, as defined by Rivlin and Tator, was used to evaluate nerve healing and its influence on motor function (17). It was observed that the inclined plane test results of the group that were administered dexpanthenol were increased in comparison to those of the SSLE group. In another experimental study investigating the effect of dexpanthenol on the healing of compression-type nerve injuries, the walking track analysis method (sciatic static index) was used for functional evaluation. The results revealed that dexpanthenol had a positive effect on functional recovery (31). The Tarlov and inclined plane tests help evaluate general locomotor abilities, but they do not reflect specific changes in motor or sensory functions (32). Although the BBB scale is more advanced than the Tarlov test, it does not provide a detailed motor function evaluation. The full measurement of fine motor and sensory function in rats is very challenging, and is a shortcoming of previous studies.

The lack of a positive control group was an important limitation of the current study. This was due to only using a small number of animals for ethical reasons (ethical committee limited the number of animals used). Another limitation of this study is that anti-oxidative and inflammatory factors were not detected directly. Instead, measurement of MDA levels, an oxidative stress marker, was used. Strengths of this study include the fact that the injury model was prepared to simulate a type of injury commonly encountered in the clinic. Peripheral nerve injuries seen in the clinic resulting in functional loss are mostly in the form of a laceration. To the best of our knowledge, in the current literature, there are no studies evaluating the effect of dexpanthenol on lacerations with a peripheral nerve injury model repaired with neurorrhaphy. In this regard, the present study may enhance clinical trials and influence the surgical treatment of nerve injuries.

Dexpanthenol was observed to have a positive effect on nerve tissue repaired with neurorrhaphy in this rat sciatic model of laceration-type injuries of the sort frequently seen in the clinic. The influence of the antioxidant and fibrosis-reducing effect on axonal healing is promising for peripheral nerve surgery.

\section{Acknowledgements}

Not applicable.

\section{Funding}

No funding was received.

\section{Availability of data and materials}

The datasets used and/or analyzed during the current study are available from the corresponding author on reasonable request.

\section{Authors' contributions}

GK and MAE conducted the experiments and wrote the manuscript. RSE and HK collected the data and performed the experiments. OE and GY designed the study. The final version of the manuscript was read and approved by all authors, and each author believes that the manuscript represents honest work.

\section{Ethics approval and consent to participate}

The Committee for Animal Research of Demiroglu Science University (approval no. 20172805-3) approved the experimental procedures. All animal studies are strictly conformed to the American Psychological Association Committee on Animal Research and Ethics Guidelines for Ethical Conduct in the Care and Use of Nonhuman Animals in Research.

\section{Patient consent for publication}

Not applicable.

\section{Competing interests}

The authors declare that they have no competing interests.

\section{References}

1. Brandon WS, Sarada S, David AS, Jacob RJ, Lynda JS and Thomas JW: An update on the management of adult traumatic nerve injuries-replacing old paradigms: A review. J Trauma Acute Care Surg 86: 299-306, 2019.

2. Rasulić L, Simić V, Savić A, Lepić M, Kovačević V, Puzović V, Vitošević F, Novaković N, Samardžić M and Rotim K: Management of brachial plexus missile injuries. Acta Clin Croat 57: 487-496, 2018.

3. Kline DG, Kim D, Midha R, Harsh C and Tiel R: Management and results of sciatic nerve injuries: A 24-year experience. J Neurosurg 89: 13-23, 1998.

4. Mark LW, Michael R, Jack GG and Pedro KB: Peripheral nerve injury, scarring, and recovery. Connect Tissue Res 60: 3-9, 2019.

5. Cho HH, Jang S, Lee SC, Jeong HS, Park JS, Han JY, Lee KH and Cho YB: Effect of neural-induced mesenchymal stem cells and platelet-rich plasma on facial nerve regeneration in an acute nerve injury model. Laryngoscope 120: 907-913, 2010.

6. Yin $\mathrm{ZS}$, Zhang $\mathrm{H}$, Bo W and Gao W: Erythropoietin promotes functional recovery and enhances nerve regeneration after peripheral nerve injury in rats. AJNR Am J Neuroradiol 31: 509-515, 2010.

7. Mahanthappa NK, Anton ES and Matthew WD: Glial growth factor 2, a soluble neuregulin, directly increases Schwann cell motility and indirectly promotes neurite outgrowth. J Neurosci. 16: 4673-683, 1996.

8. Ghoraba SM, Mahmoud WH, Elsergany MA and Ayad HM: Ulnar nerve injuries (Sunderland Grade V): A simplified classification system and treatment algorithm. Plast Reconstr Surg Glob Open 7: e2474, 2019.

9. Tulaci KG, Tuzuner A, Karadas Emir H, Tatar İ, Sargon MF, Tulaci T, Karadavut Y and Samim EE: The effect of tacrolimus on facial nerve injury: Histopathological findings in a rabbit model. Am J Otolaryngol 37: 393-397, 2016.

10. Lopatina T, Kalinina N, Karagyaur M, Stambolsky D, Rubina K, Revischin A, Pavlova G, Parfyonova Y and Tkachuk V: Correction: Adipose-derived stem cells stimulate regeneration of peripheral nerves: BDNF secreted by these cells promotes nerve healing and axon growth de novo. PLoS One 14: e0219946, 2019.

11. Klein SM, Vykoukal J, Li DP, Pan HL, Zeitler K, Alt E, Geis S, Felthaus $\mathrm{O}$ and Prantl L: Peripheral motor and sensory nerve conduction following transplantation of undifferentiated autologous adipose tissue-derived stem cells in a biodegradable U.S. food and drug administration-approved nerve conduit. Plast Reconstr Surg 138: 132-139, 2016. 
12. Lars K, Barbara $\mathrm{H}$ and Doychin NA: The pros and cons of growth factors and cytokines in peripheral axon regeneration. Int Rev Neurobiol 108: 137-171, 2013.

13. Karahan G, Kaya H, Erdogan MA, Yigitturk G, Gokyayla E and Erbas O: Effects of trimetazidine on nerve regeneration in a rat sciatic nerve injury model. Bratisl Lek Listy 120: 777-782, 2019.

14. Lundborg G: A 25-year perspective of peripheral nerve surgery: Evolving neuroscientific concepts and clinical significance. J Hand Surg Am 25: 391-414, 2000.

15. Ogden M, Karaca SB, Aydin G, Yuksel U, Dagli AT, Akkaya S and Bakar B: The healing effects of thymoquinone and dexpanthenol in sciatic nerve compression injury in rats. J Invest Surg: $1-9,2019$.

16. Demougeot $\mathrm{C}$, Marie $\mathrm{C}$ and Beley A: Importance of iron location in iron-induced hydroxyl radical production by brain slices. Life Sci 67: 399-410, 2000.

17. Rivlin AS and Tator $\mathrm{CH}$ : Objective clinical assessment of motor function after experimental spinal cord injury in the rat. J Neurosurg 47: 577-581, 1977.

18. Geuna S: The sciatic nerve injury model in pre-clinical research. J Neurosci Methods 243: 39-46, 2015.

19. Sunderland S, McArthur RA and Nam DA: Repair of a transected sciatic nerve. A study of nerve regeneration and functional recovery: Report of a case. J Bone Joint Surg Am 75: 911-914, 1993.

20. Yardimci I, Karakan T, Resorlu B, Doluoglu OG, Ozcan S, Aydin A, Demirbas A, Unverdi H and Eroglu M: The effect of intraurethral dexpanthenol on healing and fibrosis in rats with experimentally induced urethral trauma. Urology 85: 274.e9-13, 2015.

21. Ermis H, Parlakpinar H, Gulbas G, Vardi N, Polat A, Cetin A, Kilic T and Aytemur ZA: Protective effect of dexpanthenol on bleomycin-induced pulmonary fibrosis in rats. Naunyn Schmiedebergs Arch Pharmacol 386: 1103-1110, 2013.

22. Dellon AL and Mackinnon SE: Selection of the appropriate parameter to measure neural regeneration. Ann Plast Surg 23: 197-202, 1989

23. Siqueira Mietto B, Kroner A, Girolami EI, Santos-Nogueira E, Zhang J and David S: Role of IL-10 in resolution of inflammation and functional recovery after peripheral nerve injury. J Neurosci 35: 16431-442, 2015.
24. Renno WM, Benov L and Khan KM: Possible role of antioxidative capacity of (-)-epigallocatechin-3-gallate treatment in morphological and neurobehavioral recovery after sciatic nerve crush injury. J Neurosurg Spine 27: 593-613, 2017.

25. Zhang L, Johnson D and Johnson JA: Deletion of Nrf2 impairs functional recovery, reduces clearance of myelin debris and decreases axonal remyelination after peripheral nerve injury. Neurobiol Dis 54: 329-338, 2013.

26. Draper $\mathrm{HH}$ and Hadley M: Malondialdehyde determination as index of lipid Peroxidation. Methods Enzymol 186: 421-431, 1990.

27. Tutun B, Elbe H, Vardi N, Parlakpinar H, Polat A, Gunaltili M, Guclu MM and Yasar EN: Dexpanthenol reduces diabetic nephropathy and renal oxidative stress in rats. Biotech Histochem 94: 84-91, 2019.

28. Etensel B, Ozkisacik S, Ozkara E, Karul A Oztan O, Yazici M and Gürsoy H: Dexpanthenol attenuates lipid peroxidation and testicular damage at experimental ischemia and reperfusion injury. Pediatr Surg Int 23: 177-181, 2007.

29. Basso DM, Beattie MS and Bresnahan JC: A sensitive and reliable locomotor rating scale for open field testing in rats. J Neurotrauma 12: 1-21, 1995.

30. Tarlov IM and Klinger H: Spinal cord compression studies: II. Time limits for recovery after acute compression in dogs. AMA Arch Neurol Psychiatry 71: 271-290, 1954.

31. Korkmaz MF, Parlakpinar H, Erdem MN, Ceylan MF, Ediz L, Samdanci E and Kekilli E: The therapeutic efficacy of dexpanthenol on sciatic nerve injury in a rat model. Br J Neurosurg 34: 397-401, 2020.

32. Kunkel-Bagden E, Dai HN and Bregman BS: Methods to assess the development and recovery of locomotor function after spinal cord injury in rats. Exp Neurol 119: 153-164, 1993.

This work is licensed under a Creative Commons Attribution-NonCommercial-NoDerivatives 4.0 International (CC BY-NC-ND 4.0) License. 